\title{
Avengers dissemble! Transmedia superhero franchises and cultic management
}

\author{
Aaron Taylor, University of Lethbridge
}

\begin{abstract}
Through a case study of The Avengers (2012) and other recently adapted Marvel Entertainment properties, it will be demonstrated that the reimagined, rebooted and serialized intermedial text is fundamentally fan oriented: a deliberately structured and marketed invitation to certain niche audiences to engage in comparative activities. That is, its preferred spectators are often those opinionated and outspoken fan cultures whose familiarity with the texts is addressed and whose influence within a more dispersed filmgoing community is acknowledged, courted and potentially colonized. These superhero franchises - neither remakes nor adaptations in the familiar sense - are also paradigmatic byproducts of an adaptive management system that is possible through the appropriation of the economics of continuity and the co-option of online cultic networking. In short, blockbuster intermediality is not only indicative of the economics of post-literary adaptation, but it also exemplifies a corporate strategy that aims for the strategic cooption of potentially unruly niche audiences.
\end{abstract}

\section{Keywords}

Marvel Comics

superheroes

post-cinematic adaptations 
fandom

transmedia

cult cinema

It is possible to identify a number of recent corporate trends that represent a paradigmatic shift in Hollywood's attitudes towards and manufacturing of big budget adaptations. These contemporary blockbusters exemplify the new industrial logic of transmedia franchises - serially produced films with a shared diegetic universe that can extend within and beyond the cinematic medium into correlated media texts. Consequently, the narrative comprehension of single entries within such franchises requires an increasing degree of media literacy or at least a residual awareness of the intended interrelations between correlated media products. These transmedia franchises are symptomatic of two important new corporate logics: the appropriation of the economics of continuity and adaptation as strategic cultic management. Both of these logics - one adopted from the comics industry, the other responding to features of Web 2.0-era fandom - need to be identified as essential features of the adaptations produced by contemporary post-cinematic franchises. Further, the use of these logics in the production of correlated (but independently owned) Marvel 'Cinematic Universes' represents a canny attempt to co-opt and exploit the fannish expertise and subcultural influence of cultic (i.e., knowledgeable, fan-based) communities. Some might regard the growing cultural influence of digitally enabled fandom, and the potential for 'private transmissions', as the yearned-for 'mechanism of reply' to the culture industry's domineering transmissive capacity (Horkheimer and Adorno [1944] 2002: 96). Lawrence Lessig, for example, has written 
appreciatively about a purported shift from a so-called 'read-only culture' to a 'read/write culture' (2007: 76-82). Henry Jenkins has also espoused the 'immersive' and 'extractable' dimensions of transmedia storytelling, and the ensuing performative activity of the 'cultural activators' who are inspired by these texts (Jenkins 2009). Rather than unilaterally celebrating these purported developments, however, a more cautious characterization of transmedia fandom will be advanced.

\section{Continuity comics and marvel cinematic universes}

Twenty-first century transmedia franchises such as the various 'Marvel Cinematic Universes' (featuring properties presently licensed separately by Disney, 20th Century Fox, Columbia and Lionsgate) bear the trappings of the familiar and thus have the cultural currency to assert themselves prominently within a highly competitive entertainment market. Call this commoditized conspicuity. And yet such recognizability is both blessing and curse as familiarity can also breed contempt, or guarded suspicion at the very least. Fan protectorates of a franchise's exchange value are both judicious connoisseurs and exacting gatekeepers, and their supplication is now essential to the good fortunes of a highly visible

cultural product. In order to appreciate the necessity of the industry's symbolic placatory gestures - and to question their sincerity - it is necessary to analyse Marvel Studio's cultivation of fan support for their output from 2008 to 2013.

The widely trumpeted box office domination of The Avengers (2012) globally was, to a large extent, a fait accompli. Earning over $\$ 1.511 \mathrm{~b}$ worldwide (a figure that accounts for over 190 million tickets sold at an average of \$7.94), the film’s financial success can be attributed to its positioning as the zenith of a transmedia franchise at least four years in the 
making. The Avengers' box office performance is largely due to the familiarity of its wellknown antecedents. Joss Whedon's adaptation was informed by the first two series of The Ultimates (2002-2007) - Marvel Comics’ best-selling revisionist take on their longrunning Avengers series - and preceded by five other Marvel Studios movies featuring the characters who comprise the superhero team. Indeed, in many respects, the preceding five films in Disney's 'Marvel Cinematic Universe' served as feature-length trailers in a lengthy virtual ad campaign for The Avengers. Moreover, fannish investment in Iron Man (Favreau, 2008), The Incredible Hulk (Leterrier, 2008), Iron Man 2 (Favreau, 2010), Thor (Branagh, 2011) and Captain America: The First Avenger (Johnston, 2011) all but ensured that the film would be perceived by the public at large as the series' apotheosis. But what form of tribute to fans of an enduring cultural franchise was suitable in order to maximize these adaptations' exchange value, and how did media producers circumvent fans' reactionary contempt? In other words, how is the commoditized conspicuity of an adaptation affected by the electronic networks of expansive fandom? The answer lies in unearthing the business logics that allow for the proliferation of these transmedia franchises - properties that complicate easy distinctions between source text and adaptation, reader and viewer, producer and user, advertiser and consumer.

To be clear, the importance of the film industry's recent appropriation of the economics of continuity - largely pioneered by the comics industry - cannot be understated. Comic book continuity is the systematic dispersal of essential story events throughout a series and various interrelated titles. It is possible, for example, for an 'event' storyline such as Marvel's Civil War (2006-2007) to crossover between an initiating eponymous mini-series, The Avengers and its related spin-off titles, each team member's 
solo title(s), as well as other flagship franchises in the interconnected and deliberately expansive Marvel Universe. Such formidably complex intertexuality serves to define and delimit the comic industry's audience (Pustz 1999: 129). That is, comic fans can be considered as a super-niche whose members derive an exploitable pleasure from their expert knowledge of intricate swathes of historical continuity. Corporate authors therefore strive to reward fan's specialist knowledge - not because fans simply take pleasure in recognizing references to other comic texts, but because their narrative comprehension of these densely intertexual stories is reliant on such recognition.

On the one hand, continuity helps manufacture a perceived narrative depth by giving both readers and creators a sense of tradition and history from which to draw. On the other hand, continuity serves as a potential barrier to casual audiences. Readers often have to be familiar with years of back history and significant story events occurring in other titles simply to comprehend the action in a single issue. The two largest publishers, Marvel and DC, have attempted to address this problem in a concentrated manner since the comics market crash of the 1990s. One recurring strategy is the advertising of good 'jumping on' issues. Another more ambitious tactic is the occasional attempt to wipe the continuity slate clean. This calculated erasure can be achieved in two ways: (1) by introducing 'noncanon/alternative Universe' imprints, such as Marvel's Ultimate titles in 2000 (which effectively 'reboot' flagship titles but don't affect official - i.e., so-called 'Earth 616' continuity); or (2) by undertaking major continuity revisions - i.e., retcons - that retroactively excise (by editorial fiat) years of contradictorily compounding story events, such as DC's New 52 initiative in 2011. And yet, the growth of the direct market, comics' acceptance by 'legitimate' book retailers, and the limited attempts to promote comics to 
casual readers has broadly resulted in the preponderance of literacy-dependent comics i.e., comic narratives written (nearly exclusively) for fans.

The Ultimates is an example of the profitability of the strategy - especially considering that the non-canon (or 'Earth 1610') counterpart to The Avengers was the bestselling single comic issue of 2002, and issues \#2 through \#7 all placed within the top 50 (Miller). The Ultimates' first 26 issues represent, in effect, an extensive intertextual and fan-oriented rewriting/mash-up of key Earth 616 Avengers storylines: the formation of the team, conflict with the Hulk and battle with Loki (Avengers \#1, 1963); the discovery and re-animation of a frozen Captain America (Avengers \#4, 1964); and the inclusion of elements from the 'Kree-Skrull War' arc (Avengers \#89-97, 1971-1972). In turn, all of these elements inform the basic storyline of the 2012 film adaptation (which in turn establish their own filmic 'Earth 19999' continuity). The attraction for fans is noting the ways in which writer Mark Millar and artist Bryan Hitch repurpose the elements for a twenty-first-century context: Captain America as man out of time, Iron Man as irreverent playboy, Hulk as failed Super-Soldier experiment, Thor as environmental activist, the Skrulls as the shape-shifting, hive-minded 'Chitauri'. Thus the series functions as a strategically crafted transparency - a kind of adaptive layering that 'allows for the possibility of seeing through one [text] ... to another and acknowledges that the effect of simultaneity might draw on understandings built up through time and knowledge' (Geraghty 2007: 195). While The Ultimates is a non-canon reboot of a regular continuity series to help attract new readers, it still functions as a site of intertextual play for older fans for whom its revisions are also intended.

The crucial development to note here, then, is that twenty-first century Hollywood 
has likewise learned to cultivate its own brand of literacy-dependent products. What the cultivation of (at least two) Marvel Cinematic Universes demonstrates is a canny understanding of a number of lessons absorbed from the comics industry. These include: structurally essential reciprocal exchanges and the deferral of closure; fan-oriented texts and creator fan employment; reboots and retcons; selective fidelity; dispersive authorship. Each of these lessons deserves separate consideration.

\section{To be continued...}

First, the potential for structurally essential reciprocal exchanges between correlated products means that Hollywood is now able to emulate the fundamental intertextuality of comic franchises. The narrative continuity of Marvel Studios' output from 2008 to the present is certainly not the film industry's first attempt at instalment narratives (Marvel had itself adapted its own cross-referencing stories to animated television in the 1980s and 1990s), but it is certainly the most ambitious (and expensive) effort. Moreover, the films not only reference each other; they are built upon strategic 'aesthetics of incompleteness' (Johnson 2012: 7). That is, 'dangling scenes and quick character teases in Marvel's films foster not just narrative expansion but also an audience participation that extends the commercial viability of the films into new media markets beyond theatrical distribution' (Johnson 2012). In particular, the films' mid-credit 'stingers' (i.e., the abrupt interruption of the film's credits with new diegetic material) help cultivate anticipation for planned sequels and franchises in development. For example, the revelation of a grinning, skull-faced villain in the final shot of The Avenger's stinger means nothing to non-fans, as neither his name nor objectives are expressed, but fannish hearts certainly skipped a beat at 
the prospect of seeing Thanos in action in Guardians of the Galaxy (Gunn, 2014) and The Avengers: Age of Ultron (Whedon, 2015). Likewise, The Amazing Spider-Man's (Webb, 2012) mid-credit stinger was constructed to spur fan purchase of the film's home release. Here, the mystery villain is only illuminated for a microsecond by a strategically brief flash of lightning (a cue which itself spurred a flurry of online speculation regarding his identity - 'It's Electro! I just know it!').

These stingers are not only mutually rewarding for both Marvel stockholders and fans alike, they can entail a moderate degree of distinctly cinephilic pleasure by inculcating relatively complex narratological effects. The post-credit stinger in Iron Man 3 (Black, 2013), for example, reveals a therapy session in progress between Tony Stark (Robert Downey Jr) and a 'therapist' who has been fighting off sleep. Avengers viewers recognize this dozy doctor as the Hulk's alter-ego, Bruce Banner (Mark Ruffalo), but the stinger also provides an inter-diegetic context for Stark's voice-over narration heard throughout the film - narration we had assumed to be extra-diegetic. This discursive shift is a minor aesthetic 'reward' to Marvel fans who have been conditioned to expect additional narrative information after the credits, and Ruffalo's cameo as Banner also reinforces Iron Man 3's position within an ongoing serial and multimodal franchise. Likewise, the single most amusing instance in Fox's X-Men: First Class (Vaughn, 2011) involves a surprising instance of thwarted (or at least postponed) transmedial storytelling. A five-second cameo by Wolverine (Hugh Jackman) consists of the scrappy Canuck instructing a young Charles Xavier (James McAvoy) and Magneto (Michael Fassbender) to 'Fuck off', before they can even begin to invite him to join their newly founded team. Thus, the films emulate the comics industry's deferral of closure by crafting cross-referencing serial narratives that can 
develop in perpetuity.

The twenty-first century proliferation of structurally integrated and serialized comic book franchises has to be understood within a broader industrial convergence culture. Since the mid-2000s, Hollywood studios have changed their economic relationship with Marvel Entertainment. The latter is now a source of contractual labour for the former, rather than vice versa, and (the briefly independent) Marvel Studios has gone to considerable lengths to gain control of the industrial labour and convergence relationships involving its creative properties (Johnson 2012: 14-15). Marvel's reinvented corporate identity as a transmedia character licensor helps explain why it is more accurate to speak of 'Marvel Cinematic Universes' in the plural. Between 2000 and 2012, five separate production companies traded in the rights to adapt Marvel comic book properties. Aside from Marvel Studios, Fox has numerous cinematic continuities based around its licenses for $X$-Men (Singer, 2000) and the Fantastic Four (relinquishing its Daredevil license to Marvel in 2012). In addition, Columbia has established two separate continuities for its Spider-Man productions (relinquishing its Ghost Rider license in 2013). In recent years, both New Line and Lionsgate relinquished their licenses to their respective Blade and Punisher franchises. And while competing licenses make it near-impossible for the studios to combine Universes, the established box-office successes of many of these productions will ensure the institutionalization of reciprocal film and comics convergence. Thus, the appropriated logics of comic continuity are subject to the economic logics of licensing and trade.

\section{The receptive tactics and creative strategies of true believers}

These exchanges obviously foster the production of fan-oriented texts that reward 
expert (because habitual) consumers. Indeed, these adaptations have more or less normalized a once esoteric and subcultural activity - i.e., the 'fan mode of interactive and intertextual engagement' with transmedia franchises (Daly 2010: 85). Comparative activities were previously undertaken by knowledgeable specialists as exercises in the display of arcane trivia; they are now invited as the normative response to franchise adaptations that strive to interpellate the ordinary viewer as a fan (call this cultic ubiquity). Christine Geraghty reminds us that adaptations are distinct as a genre in that they acknowledge the process by which familiar material is recontextualized, and in turn invite viewers to share in the pleasure of this acknowledgment (2007: 5). But the industrial rebranding of certain adaptations and/or remakes as 'reimagined' or 'rebooted' properties speaks to the subcultural authority and influence of fans' literacy - i.e., their familiarity with and proprietary investment in these recontextualizations. ${ }^{1}$ Fans are encouraged to identify obscure references, teases, in-jokes, graphic semblances, knowing revisions and disseminate their knowledge across various information ecosystems.

We might consider, for example, the playful graphic back and forth exchanges between The Ultimates comic series and Marvel Studios' various film productions. In the first two volumes of The Ultimates, Millar and Hitch delighted in visually modelling their revised versions of regular continuity characters after established Hollywood stars. Most obviously, their graphic recasting of Nick Fury (a grizzled, Caucasian S.H.I.E.L.D. director in regular continuity) as a bald, African American colonel with an uncanny resemblance to Samuel L. Jackson proved a rich semiotic tactic to inculcate fannish pleasure. Fury himself even remarks on this similarity in Ultimates Vol. 1 \#4 (2002), in which he jokingly identifies the stars that ought to play the heroes in the Hollywood version of the team's 
exploits. $^{2}$

Of course, these fictional 'casting' scenario would lead to actual ones. To the delight of fans, Jackson negotiated for the role of Fury in Marvel Studios' filmic adaptations (rather than litigate for unauthorized usage of his likeness). As a fan-oriented film, The Avengers works in an impressive degree of layered arcana. A pivotal plot point, for example, revolves around Fury manipulating the dispirited Avengers back into action by presenting them with a fallen colleague's blood-stained Captain America trading cards. A close-up of the cards reveals them as an admixture of film-specific artefacts (they bear actor Chris Evan's likeness), while others feature vintage comic book art by seminal Captain America artists Jack Kirby and Joe Simon. Such subtle hailing is, of course, commodifiable: one can order 'Agent Coulson's Vintage Captain America Trading Card Set' from eFx for $\$ 40$ (including a blood-stained version of the set). The goal of these fanoriented texts, as to be expected, is to establish virtual feedback loops ('mechanisms of reply') to engage in comparative discourse in the form of blogs, wikis, metadata tagging, mashups, etc. - all of which ultimately serve as dispersive advertising for the studio's products.

Just as fans are prompted to engage in their own creative activity and knowledge dissemination, one should take note of the concomitant Hollywood practice of contracting of celebrity creator fans with a considerable knowledge of comic book properties to helm or write their superhero adaptations. The comics industry has long understood the importance of cultivating the paradoxical notion that corporate authors are also fans. On the one hand, mainstream companies now largely embrace a closed shop labour model by assigning artists and writers with cult indie hits or proven track records in other media. On 
the other hand, however, even though the majors no longer acquire untried fan talent (e.g., offering assistant editing jobs to regular 'letterhacks' [fan letter writers], or trial runs to fan artists whose portfolios are observed at conventions), corporate artists nearly always make public declarations as self-professed fans. These are articulated via internal platforms (such as Marvel's now-defunct 'Bullpen Bulletin' announcements within their comics, and corporate websites), or external platforms such as press releases or interviews. Fan creators also typically foster various channels of direct contact with their audience (now-defunct letter columns, convention appearances, Reddit forums, Twitter exchanges, etc.). From the examples cited here, a number of these fan-oriented tactics clearly precede the so-called 'producer culture' of new media production (Ross 2010: 912-13). ${ }^{3}$

Within this producer culture, however, the proliferation of user-generated content by talented amateurs speaks to the increasing value of fan's 'experience-based expertise' i.e., skillsets and propositional knowledge gleaned from social immersion within an expert (subcultural) group (Ross 2010: 921). In order to cultivate the commoditized conspicuity of its superhero adaptations, then, Hollywood recognizes the irreplaceable worth of 'referred expertise - an expertise imported from one field...into another' (Ross 2010, original emphasis). Thus, they are careful to import talent with a substantial degree of experiencebased expertise within fan communities. The hiring of Joss Whedon to helm The Avengers is an emblematic example. Presiding over a number of cult media hits - collectively referred to as 'the Whedonverse' - Whedon is also a professional creator who recognized the (monetary) importance of maintaining (the image of) direct accessibility to fans prior to the advent and ubiquity of social media. Canny career imaging as a self-professed feminist also helped Whedon develop a devoted critical and broadly female fan base. The weblog 
WHEDONesque testifies to his subcultural capital as fan-creator: the site generates 'close to 100,000 words of text from over 200 members of WHEDONesque, responses that represent a wide range of ideas related to issues of gender, social justice, and politics' (Cochran 2012: 3.1). By embedding numerous references to The Avengers within fanbeloved TV series Buffy the Vampire Slayer (1997-2003), Whedon reinforced his experience-based expertise as a fanboy, and proleptically ensured his suitability as director of the 2012 adaptation of the comic series.

Marvel Studio's savvy appropriation of Whedon's referred expertise is further buttressed by other complex industrial examples. In September 2012, Fox hired Ultimates co-creator Mark Millar as 'Creative Consultant' to oversee their forthcoming Marvel adaptations. Marvel Studios CEOs Avi Arad and Kevin Feige have also carefully spun their personal fandoms as quasi-moral obligations to honour the wishes of their community, thus providing a perceived ethics that authenticates their own careerism (Johnson 2012: 16-18). A studio's use of referred fan expertise can also serve as a suitably cultic acknowledgement of subcultural audiences. In hiring Kenneth Branagh to direct Thor, for example, Marvel invited fans to recognize Branagh's experience-based expertise as a producer of and actor within numerous stage and screen adaptations of Shakespeare. Branagh's hiring is a meaningful sign of the production company's subcultural credibility: it recognizes fanknowledge that Thor's co-creator, Stan Lee, frequently trumpeted the 'Shakespearean' quality of his comic series (1963-1971). In this way, corporate poaching of fan creators can establish complexly pleasurable (and profitable) paratexts between comic book source texts and filmic hypertexts.

It should be obvious, then, that these strategic hiring practices subsequently help to 
attract subcultural capital and the investment of fan-consumers. For example, the cynicism of the discriminating spectator is placated rather than dismayed at the prospect of 'reimagined' versions of Superman because the character-brand is revised by trusted, fanfavourite auteurs with 'respectable' track records in handling comic book properties. Bryan Singer's 'quality' cinematic treatments of X-Men (2000) and X2 (2003) allow for the director's 'radical' messianic treatment of DC's iconic commodity in Superman Returns (2006). Or, Zack Snyder's literalist approach to fidelity in adapting 300 (2006) and Watchmen (2009) validates the visual bombast (if not the conceptual idiocy) of his take on the Man of Steel (2013). Similarly, Marvel draws on James Gunn's indie cred as the writer and/or director of satirical superhero ventures, The Specials (Mazin, 2000) and Super (Gunn, 2010) by assigning him to (the considerably more costly) Guardians of the Galaxy (Gunn, 2014). More to the point, the financial risk of adapting Marvel's decidedly D-list property, Ant-Man (Wright, 2015), is somewhat alleviated by allocating its direction to cult favourite, Edgar Wright - adaptor of the equally cultic comic, Scott Pilgrim vs. the World (Wright, 2010).

\section{Wiping the slate}

Hollywood now also appreciates the creative and fiscal opportunities generated by franchise reboots and retcons - the periodic erasure of years' worth of continuity across intersecting franchises in order to tidy up byzantine narratives, usher in new creative teams, and/or jettison unpopular story developments. Through a strategically serendipitous transmedial exchange, then, Columbia cannily ensured that their 2012 rebooting of the Spider-Man film franchise - a mere five years after the last entry (Spider-Man 3 [Raimi, 
2007]) - was not widely perceived as a desperate gesture to acquire an extension of their licensing agreement with Marvel Entertainment. And yet, the reason for the Marc Webbdirected reboot of The Amazing Spider-Man was, in fact, fundamentally mercenary. In January 2010, previous director Sam Raimi abandoned 'Spider-Man 4' during preproduction, citing dissatisfaction with the story and the intended rushed release date of May 5 (Finke 2010). This date complied with the terms of Columbia's licensing deal, which required them to produce a Spider-Man film every five years. Not wishing for the production delay to cause Columbia's rights to the character to revert back to Marvel in 2012, an executive decision was made to reboot the series (Kendrick 2012). Recycling Spider-Man's origin story was largely a matter of expediency, as the source material served as a time-saving readymade template for principal screenwriter James Vanderbilt. It also avoided the undesirable disruption to franchise continuity by replacing Raimi (a fan favourite) and, more visibly, original stars such as Tobey Maguire and Kristen Dunst. With Marvel Entertainment/Disney trying to consolidate its control of its various extremely profitable properties, Columbia's quickie reboot staved off the company's loss of its licensing rights to the character. Such a loss was suffered by Fox, whose rights to Daredevil expired in August 2012 after the company failed to greenlight Joe Carnahan's planned reboot of the franchise (Lemon 2012).

But as a licensee of Marvel Entertainment, Columbia needed to avoid fannish accusations of creative bankruptcy and blatant exploitation by rebooting the Spider-Man franchise so soon after its last instalment. Fortunately for Columbia, however, their reboot attained subcultural accreditation via its timely association with analogous revisions to the originating comic book series itself. Webb's film replicates the character's familiar origin 
story, but such difference-in-repetition is made palatable to elitist comics fans by the "backto-basics' approach to the character that had already been initiated within the comic series earlier in 2008. Marvel creative personnel initiated a strategic retcon in the Brand New Day story-arc (2007), which saw Peter Parker return to his put-upon, working-class, bachelorized 'roots'. It is worth noting that this retcon has implicit ideological valences. The Brand New Day story arc strategically implements a mythic return to the character's origins as a young, put-upon working class hero, but it does so by removing the 'obstruction' of Peter Parker's marriage to Mary Jane Watson. The message is clear: unrestricted individualism (read: 'superheroics') is only possible when unencumbered by the web of domestic entanglement. As we shall see momentarily, however, such implicit misogyny is clearly (and cannily) countered by the reboot of the film franchise.

\section{Intermittently faithful}

Another lesson Hollywood has learned from the comics industry is the benefit of adopting selective fidelity as a creative policy. 'Selective fidelity' should be understood as a strategic faithfulness to a franchise's culturally conspicuous narrative elements rather than the authorial intentions of a single artist figure. These elements gain both cultural and economic traction by virtue of their service as structurally necessary narrative kernels what Umberto Eco calls a comic's set of 'irreversible premises' (1972: 18). So, while Peter's marriage to Mary Jane served as a major structural element for the comics for twenty years, its mystical erasure from the series' continuity in 2007 (care of the demonic Mephisto) demonstrated their relationship to be a highly reversible premise after all. Conversely, Marc Webb's film institutes a retcon that grants centrality to Peter's earlier 
love interest, Gwen Stacy (Emma Stone). The situation of Gwen as Peter's first high school girlfriend is a rewriting of Marvel's regular continuity, as the character does not appear in the comics until The Amazing Spider-Man \#31 (1965) when Peter begins to attend (the fictional) Empire State University. Indeed, during his tenure at Midtown High, Peter's affections are initially directed towards (but not returned by) the haughty Liz Allan, and Betty Brant - the Girl Friday of his tyrannical boss at The Daily Bugle, City Editor J. Jonah Jameson. Needless to say, none of Peter's love interests in Marvel's regular continuity were privy to actively sharing in his superheroic career until 1984, when Mary Jane reveals in Amazing Spider-Man \#257 that she knows his secret identity.

The 2012 film's most important revision to the Spider-Man mythos as a whole, then, is that Gwen does share Peter's (Andrew Garfield) secret, and acts as his romantic and professional partner. Indeed, the film is a superheroic romantic comedy of sorts. And unlike the earlier filmic trilogy (2002-2007), in which Mary Jane is largely presented as an encumbrance or outsider who must be 'protected' from the dangers of the hero's career as arachnoid vigilante, Marc Webb's reboot allows for the possibility of a relationship of equals. Gwen brokers a relationship of understanding and respect between Peter and her father, George (Dennis Leary) - who also doubles as a figure of legal authority as an NYPD Captain. Her courage and ingenuity in facing the villainous Lizard (Rhys Ifans) also assures Peter's first major victory over a superhuman threat. Emma Stone's performative vibrancy and humour are foregrounded, and crucially they allow fans the opportunity to view Gwen as an embodied and vital presence - an innovative and important tactic given the reductive function of the character in the comics. There, she is simply 'the Girl Who Died'. The character's sudden murder by the Green Goblin - in Amazing Spider-Man \#121 
(1973) - is often cited as an event that marked the passage of the so-called Silver Age of comics (major characters rarely died unexpectedly and permanently in mainstream comics). But Gwen's death has since been reduced to another signifier that demarcates Spider-Man's operative characteristic - that of guilt (i.e., he fails to save her from a fall from George Washington Bridge - indeed, it is implied that his webbing may have snapped her neck). Most crucially, then, by granting centrality to the character, and establishing romantic partnership as the core structural element of the Spider-Man series, the 2012 film allows fans the opportunity to view Gwen as so much more than just a victim of masculinist pathology.

So, just as aspects of Parker's evolving identity as an aging superhero are systematically excised from the comics in the Brand New Day story arc (e.g., his marriage, a steady income, public accreditation), the film can coincidentally embark on a literal representation and rewriting of the character's adolescent origins. Thus, the film's replaying of Spider-Man's teenaged beginnings retains interest for discriminating niche audiences who might otherwise have been jaded by the trotting out of an all-too-familiar tale. Comic fans happily attend the film already primed by the source text's 'restoration' of the narrative elements that Marvel imagined to be vital to the character's enduring popularity.

\section{The definitive version(s)}

The cultivation of dispersive authorship allows for comparative assessments of different 'versions' of a property by distinctive authorial voices. The comics industry has long understood the exchange value of its own star creator system. Indeed, in the 1990s, freelance artists themselves began to broker more lucrative contracts and previously 
unimagined degrees of creative control over their intellectual property. Thus, while workfor-hire or freelance artists employed by major comic companies may not enjoy full creative rights over the products upon which they labour, their distinctive contributions do provide their output with an author-brand appeal. Significantly, it is the fans who bestow the work of star artists with considerable exchange value. To speak of 'Frank Miller's Daredevil' or 'Brian Michael Bendis' Daredevil' is to bestow a collectively and corporately authored property with singular artisanal value. This value is critical (each writer/artist articulates a 'definitive' version of the Man Without Fear), monetary (near-mint copies of Miller's 1979 debut on Daredevil are valued at up to \$250), and transmedial (director Joe Carnahan frequently cited Miller as the creative inspiration for his aborted Daredevil reboot for 20th Century Fox) (Keyes 2012). These values gain cultic and commercial traction within the comic industry's dispersive authorship model.

With superhero film adaptations, then, corporate auteurs need not contend with the cultural prowess of esteemed Author figures whose personal expression and artisanal labour bestows a literary work with a distinctive and singular identity - an 'aura' so to speak. Instead, the emphasis is on the adaptation of the microtext (i.e. narrative figures 'who are assumed to be malleable within certain limits'), or macrotext (i.e. the franchise that is itself 'larger than its author') (Leitch 2007: 216). Boutique cinema, for example, manufactures a sufficient cultural equivalence for the middlebrow adaptation of a Great Book (that might translate into Oscar nominations). By contrast, the microtexts or macrotexts crafted by a comic book property gain legitimation from strategically courted fan bases.

In addition, superheroes are microtexts ripe for transmedia adaptation as they serve 
as consistent prototypes with a remarkable degree of narrative malleability. Looking at the example of DC's Batman, Will Brooker asserts, 'the character seems to become merely a name and logo adapted by a multitude of different "Batmen", each representing a different facet of a specific cultural moment and taking on the concerns of a period or the tastes of an audience' (2000: 39). Hence, comic fans of the late 1980s would unsurprisingly be desirous of a Dark Knight, rather than a campy Caped Crusader. Two major comic publications of the late 1980s were Batman graphic novels that helped a perceived kiddie industry achieve a newfound mainstream respectability: The Dark Knight Returns by Frank Miller (1986) and The Killing Joke by Brian Bolland and Alan Moore (1988). The latter text is noteworthy for its assertion that Batman and his clownish nemesis, the Joker, are inextricably bound together by different varieties of the same psychosis - a symbiotic interrelationship explicitly commented upon within the film. Indeed, screenwriter Sam Hamm acknowledged the influence of The Killing Joke on his script for Tim Burton's 1989 version of Batman, and apparently consulted with Alan Moore on the film's tone (Smith and Matthews 2010: 69). The result of this non-committal name-dropping in pre-publicity: the assuagement of fan outrage (at Warner Bros.' 'audacity' in hiring an 'unsuitably comic' Michael Keaton in the title role) and the circumvention of competing authorial claims to a 'definitive’ Batman. Fifteen years later, Zack Snyder and Roberto Rodriguez would take a much more literalist approach to this lesson, wooing fanboys by promising them brushstroke-perfect filmic translations of Frank Miller's distinctive visual style in Sin City (Rodriguez, 2005) and 300.

Thus, franchise film-makers have learned to adopt the decades-old authorial mechanics of the comic industry, whereby 'each new version [of a given property] 
challenges the authority of all previous versions so that no version of events... is definitive, and any new version is likely to become as definitive as any other' (Leitch 2007: 234). But is this democratic potential for 'definitiveness' as likely as Leitch indicates here? That is, did such potential 'definitiveness' extend to 'Mark Steven Johnson's Daredevil (2003)?' The fans didn't think so, as evidenced by the film's woeful 5.4 user rating at IMDb and broad reputation as a dud. Thus, the commoditized conspicuity of a transmedia adaptation remains at the mercy of subcultural gatekeepers.

\section{Conclusions}

Thus, the reimagined, rebooted and serialized transmedia text is fundamentally fan oriented: it is a deliberately structured and marketed invitation to certain niche audiences to engage in comparative activities. That is, its preferred spectators are often those opinionated and outspoken fan cultures whose familiarity with the texts is addressed and whose influence within a more dispersed film-going community is acknowledged, courted and (potentially) colonized. For Henry Jenkins, the synergistic practices of transmedia franchises compound the interactive potential of extratextually expanded narrative universes since "transmedia promotion presumes a more active spectator who can and will follow these media flows. Such marketing strategies promote a sense of affiliation with and immersion in fictional worlds' (Jenkins 2002: 147). And yet these franchises - neither remakes nor adaptations in the familiar sense - are also paradigmatic byproducts of an adaptive management system that is possible through the appropriation of the economics of continuity and the co-option of online cultic networking. The aim of this contemporary industrial practice is to harness and regulate the creative energies of both film-makers and 
fans. In short, blockbuster transmediaity is not only indicative of the economics of postcinematic adaptation, but it also exemplifies a corporate strategy that aims for the strategic co-option of potentially unruly niche audiences. The transmedia circulation of comic properties thus bespeaks a fundamental ambivalence involving the use-value of postcinematic adaptations in the age of new media: while they serve as catalyzers for fannish mechanisms of reply, they simultaneously serve as dominant channels by which the culture industry co-opts and regulates subcutltural energies.

\section{References}

Anon. (2013), ‘2012 domestic gross’, Box Office Mojo, 1 January, http://www.boxofficemojo.com/yearly/chart/?yr=2012\&p=.htm. Accessed 20 May 2014.

Black, S. (2013), Iron Man 3, USA: Walt Disney Studio Motion Pictures.

Branagh, K. (2011), Thor, USA: Paramount Pictures.

Brooker, W. (2000), Batman Unmasked: Analyzing a Cultural Icon, New York: Continuum.

Cochran, T. R. (2012), "Past the brink of tacit support": Fan activism and the Whedonverses', Transformative Works and Cultures, 10, http://journal.transformativeworks.org/index.php/twc/article/view/331/295. 
Daly, K. (2010), 'Cinema 3.0: The interactive image', Cinema Journal, 50:1, pp. 81-98.

De Rosnik, A. (2013), 'Fandom as free labor', in T. Scholz (ed.), Digital Labor, New York: Routledge, pp. 98-111.

Eco, U. (1972), 'The myth of superman', Diacritics, 2:1, pp. 14-22.

Favreau, J. (2008), Iron Man, USA: Paramount Pictures. (2010), Iron Man 2, USA: Paramount Pictures.

Finke, N. (2010), 'Exclusive: “Spider-Man 4” officially has no start date as of today because of script problems; Sony "Unlikely" to make scheduled May 5, 2011, Release Date', Deadline.com, 11 January, http://www.deadline.com/2010/01/urgent-spider-man-4scrapped-as-is-raimi-and-cast-out-franchise-reboot-planned/. Accessed 20 May 2014.

Geraghty, C. (2007), Now a Major Motion Picture: Film Adaptations of Literature and Drama, Lanham: Rowman \& Littlefield.

Gunn, J. (2010), The Super, USA: IFC Films. (2014), Guardians of the Galaxy, USA: Walt Disney Studios Motion Pictures. 
Horkheimer, M. and Adorno, T. ([1944] 2002), 'The culture industry: Enlightenment as mass deception', in G. S. Noerr (ed.), Dialectic of Enlightenment (trans. E. Jephcott), Standford: Stanford University Press, pp. 94-136.

Jenkins, H. (2002), 'Interactive audiences? The "Collective Intelligence” of media fans', in H. Jenkins (ed.), Fans, Bloggers, and Gamers: Exploring Participatory Culture, New York: New York University Press, pp. 134-51.

(2009), 'Revenge of the origami unicorn: The remaining four principles of transmedia storytelling', Confessions of an Aca-Fan, 12 December, http://henryjenkins.org/2009/12/revenge_of_the_origami_unicorn.html. Accessed 20 May 2014.

Johnson, D. (2012), 'Cinematic destiny: Marvel studios and the trade stories of industrial convergence', Cinema Journal, 52:1, pp. 1-24.

Johnson, M. S. (2003), Daredevil, USA: Twentieth Century Fox Film Corporation.

Johnston, J. (2011), Captain America: The First Avenger, USA: Paramount Pictures.

Kendrick, B. (2012), 'The Amazing Spider-Man producers planned for (at the very least) a new trilogy', Screenrant.com, July, http://screenrant.com/the-amazing-spiderman-movietrilogy-benk-184764/. Accessed 20 May 2014. 
Keyes, R. (2012), 'Joe Carnahan's Daredevil Sizzle Reel', ScreenRant, September, http://screenrant.com/daredevil-reboot-joe-carnahan/. Accessed 20 May 2014.

Lee, C. (2012), 'Answered: Which studios own which marvel characters', ScreenRant, January, http://screenrant.com/marvel-comics-movies-characters-carl-6766/. Accessed 20 May 2014.

Leitch, T. (2007), Film Adaptation and its Discontents, Baltimore: Johns Hopkins University Press.

Lemon, M. (2012), 'Daredevil film rights returning to marvel studios', The Escapist, 15 August, http://www.escapistmagazine.com/news/view/119075-Daredevil-Film-RightsReturning-to-Marvel-Studios. Accessed 20 May 2014.

Lessig, L. (2007), Remix, London: Bloomsbury.

Leterrier, L. (2008), The Incredible Hulk, USA: Universal Pictures.

Mazin, C. (2000), The Specials, USA: Regent Entertainment.

Miller, J. J. (2002), ‘Aggregated 2002 comic book sales figures', The Comics Chronicles, http://www.comichron.com/monthlycomicssales/2002.html. Accessed 1 May 2013. 
Pustz, M. J. (1999), Comic Book Culture, Jacksonville: University Press of Mississippi.

Raimi, S. (2007), Spider-Man 3, USA: Columbia Pictures.

Rodriguez, R. (2005), Sin City, USA: Dimension Films.

Ross, P. (2010), 'Is there an expertise of production? The case of new media producers', New Media and Society, 13:6, pp. 912-28.

Russo, A. and Russo, J. (2014), Captain America: The Winter Solider, USA: Walt Disney Studios Motion Pictures.

Singer, B. (2000), X-Men, USA: Twentieth Century Fox. (2003), X2, USA: Twentieth Century Fox. (2006), Superman Returns, USA: Warner Bros.

Smith, J. and Matthews, J. C. (2010), Tim Burton, London: Virgin Books.

Snyder, Z. (2006), 300, USA: Warner Bros. 

(2009), Watchmen, USA: Warner Bros. (2013), Man of Steel, USA: Warner Bros.

Tarantino, Q. (1994), Pulp Fiction, USA: Miramax Films.

Taylor, A. (2013), 'How to see things differently: Tim Burton's reimaginings', in J. A. Weinstock (ed.), The Works of Tim Burton, New York: Palgrave Macmillan, pp. 99-116. Vaughn, M. (2011), X-Men: First Class, USA: Twentieth Century Fox Film Corporation. Webb, M. (2012), The Amazing Spider-Man, USA: Columbia Pictures.

Whedon, J. (2012), The Avengers, USA: Walt Disney Studios Motion Pictures. (2015), The Avengers: Age of Ultron, USA: Walt Disney Studios Motion Pictures. (1997-2003), Buffy the Vampire Slayer, USA: WB Television Network and UPN.

Wright, E. (2010), Scott Pilgrim vs. the World, USA: Universal Pictures. (2015), Ant-Man, USA: Walt Disney Studios Motion Pictures. 


\section{Contributor details}

Aaron Taylor is an Associate Professor in the Department of New Media at the University of Lethbridge. He is the editor of Theorizing Film Acting (2012) and his most recent publications on performance can be found in Millennial Masculinity (2013), Quarterly Review of Film and Video (2012), Acting and Performance in Moving Image Culture (2012), Stages of Reality: Theatricality in Cinema (2012), Studies in Documentary Film (2011) and The Journal of Film and Video (2007). His additional work on cultic management can be found in The Works of Tim Burton (2013).

Contact:

Aaron Taylor, University of Lethbridge, Department of New Media, Centre for the Arts W864, 4401 University Drive, Lethbridge, Alberta, T12K 3M4, Canada.

E-mail: aaron.taylor2@uleth.ca

Notes

${ }^{1}$ I also discuss reimagined properties as a corporately conceived taste category and their role in cultic management in my work on Tim Burton's adaptations (Taylor 2013: 99-116).

${ }^{2}$ The complexity of this sly cross-referentiality is amplified further in Captain America: The Winter Soldier (Russo and Russo, 2014). Here Nick Fury's mock-tombstone features a quote 
from Ezekiel 25:17 - a near-subliminal nod to Jackson's celebrated usurpation of the Biblical verse in Pulp Fiction (Tarantino, 1994). The decommissioned Col. Fury might also be said to be 'walking the earth' at the conclusion of Winter Solider just as Jules Winfield does at the end of Pulp Fiction.

${ }^{3}$ My thanks to Christine Clark for introducing me to Ross' helpful article. 